\title{
ANALISIS TINGKAT KERAGAMAN PENGUKURAN VOLUME KAYU BULAT OLEH TENAGA TEKNIS PENGELOLAAN HUTAN PRODUKSI LESTARI (GANIS- PHPL) PADA APLIKASI SI-PUHH ONLINE
}

\author{
ANALYSIS LEVEL OF DIVERSITY MEASUREMENT VOLUME OF ROUND WOOD BY \\ TECHNICAL PERSONNEL FOR SUSTAINABLE PRODUCTION FOREST MANAGEMENT \\ (GANIS-PHPL) ON SI-PUHH ONLINE APLICATION
}

\author{
Isak W. Silooy ${ }^{1)}$, G. Mardiatmoko ${ }^{2)}$, Rohny. S. Maail ${ }^{3)}$ \\ Program Magister Manajemen Hutan Universitas Pattimura Ambon \\ Jl. dr.Latumeten Kampus PGSD Ambon \\ Email : chaken.silooy@yahoo.com
}

\begin{tabular}{|l|l} 
Diterima : 2 Agustus 2019 & Disetujui : 20 Agustus 2019
\end{tabular}

\begin{abstract}
Abstrak
penelitian ini bertujuan untuk menganalisis Manganalisis tingkat keragaman pengukuran volume kayu bulat dilapangan antara peneliti dengan Tenaga Teknis Pengelolaan Hutan Produksi Lestari (GANISPHPL) yang diinput pada aplikasi SI-PUHH Online. Metode yang digunakan adalah metode kuantitatif dengan mengembangkan model dengan mengembangkan model-model matematis (perhitungan), yang berkaitan dengan pengukuran kayu bulat. Hasil penelitian menunjukkan bahwa Tenaga Teknis Pengelolaan Hutan Produksi Lestari (GANIS-PHPL) yang dimiliki PT. Gema Hutani Lestari tidak cermat dalam melakukan tugas dan kewenangannya dalam mengukur kebenaran volume kayu bulat, karena telah terjadi kelebihan toleransi volume sebesar 5,97\% dari batas toleransi volume yang ditetapkan sebesar $5 \%$, sehingga menimbulkan unsur kerugian Negara. Dengan demikian Kinerja dan peranan GANIS-PHPL dipandang perlu dilakukan pembinaan dan pengendalian terkait dengan tugas dan kewenangannya dalam hal melakukan pengukuran dan pengujian volume kayu bulat, sehingga perhitungan penerimaan negera bukan pajak (PNBP) mencapai target yang diinginkan.
\end{abstract}

Kata kunci : Pengukuran volume, kayu bulat, SI-PUHH Online

\begin{abstract}
Absract
Therefore this study aims to analyze the level of diversity in the measurement of volume of logs in the field between researchers and Technical Personnel for Sustainable Production Forest Management (GANIS-PHPL) inputted in the SI-PUHH Online application. The method used is a quantitative method by developing models mathematical (calculations), which are related to the measurement of logs. The results showed that the Technical Personnel for Sustainable Production Forest Management (GANISPHPL) owned by PT. Gema Hutani Lestari is not careful in carrying out its duties and authorities in measuring the correctness of the volume of logs, because there has been an excess volume tolerance of $5.97 \%$ of the set tolerance limit of $5 \%$, giving rise to an element of state losses. Thus the performance and role of GANIS-PHPL is deemed necessary for guidance and control related to its duties and authority in terms of measuring and testing the volume of logs, so that the calculation of non-tax state revenue (PNBP) reaches the desired target.
\end{abstract}

Keywords : Measurement of volume, Round Wood, SI-PUHH Online

DOI: 10. 30598/jhppk. 2019

ISSN ONLINE: 2621- 8798 


\section{PENDAHULUAN}

Sebagai salah satu kekayaan alam yang menjadi modal dasar pembangunan nasional, hutan memiliki manfaat yang nyata bagi kehidupan dan penghidupan masyarakat, baik itu manfaat ekologi, sosial, budaya maupun ekonomi. Sejalan dengan pasal 33 undangundang dasar 1945 sebagai landasan konstitusional yang mewajibkan agar bumi, air dan kekayaan alam yang terkandung di dalamnya dikuasai oleh negara dan dipergunakan sebesarbesar kemakmuran rakyat. Hal ini mengisyarakan bahwa penyelenggaraan kehutanan senantiasa mengandung jiwa dan semangat kerakyatan, berkeadilan dan berkelanjutan, untuk itu hutan harus dikelola dan dipelihara secara berkesinambungan bagi kesejahteraan masyarakat, baik untuk generasi sekarang maupun yang akan datang. (Undang-Undang Nomor 41 Tahun 1999).

Paradigma baru sektor kehutanan memandang hutan sebagai sistem sumberdaya yang bersifat multi fungsi, multi guna dan mencangkup multi kepentingan serta pemanfaatannya diarahkan untuk mewujudkan sebesar-besarnya kemakmuran rakyat. Paradigma ini menyadarkan kita bahwa produk hasil hutan bukan kayu (HHBK) merupakan salah satu sumberdaya hutan yang memiliki keunggulan komparatif dan paling bersentuhan dengan masyarakat sekitar hutan. HHBK terbukti dapat memberikan dampak pada peningkatan penghasilan masyarakat sekitar hutan dan memberikan kontribusi yang berarti bagi penambahan devisa negara, maka pembangunan produk HHBK ditujukan pada pemberdayaan, dan peningkatan sumberdaya hutan, ekonomi rakyat serta peningkatan devisa negara (Manuhuwa, 2009).

Luas kawasan hutan Provinsi Maluku berdasarkan Surat Keputusan Menteri Kehutanan Nomor : 854/Menhut-II/2014 tanggal 29 September 2014 sebesar 3.919.617 hektar, terdiri atas Hutan Konservasi (HK) 429.538 hektar, Hutan Lindung (HL) 625.256 hektar, Hutan Produksi Terbatas (HPT) 894.258 hektar, Hutan Produksi (HP) 643.699 hektar, dan Hutan Produksi Konversi (HPK) 1.324.866 hektar. Luas kawasan hutan Provinsi Maluku dapat dilihat pada Tabel. 1.

Berdasarkan Neraca Sumber Daya Hutan (NSDH) Maluku, perkiraan potensi kayu dari kawasan hutan di Provinsi Maluku yaitu hutan primer $35.625,324 \mathrm{~m}^{3}$, hutan sekunder 124.689.960 $\mathrm{m}^{3}$, dan non hutan sebesar $166.856 .361 \mathrm{~m}^{3}$, dengan total perkiraan potensi kayu di Maluku sebesar 393.741.322 $\mathrm{m}^{3}$.

Tabel 1. Luas kawasan hutan Provinsi Maluku menurut fungsi

\begin{tabular}{llcc}
\hline No & \multicolumn{1}{c}{ Fungsi Hutan } & $\begin{array}{c}\text { Luas } \\
(\mathrm{Ha})\end{array}$ & Prosentase $(\%)$ \\
\hline 1. & Hutan Konservasi & 429.538 & 10.96 \\
2. & Hutan Lindung & 627.256 & 16.01 \\
3. & Hutan Produksi Terbatas & 894.258 & 22.81 \\
4. & Hutan Produksi & 643.699 & 16.42 \\
5. & Hutan Produksi yang Dapat Dikonversi & 1.324 .866 & 33.8 \\
\hline \multicolumn{2}{r}{ Jumlah } & 3.919 .617 & 100.00 \\
\hline
\end{tabular}


Dari potensi kayu tersebut terdapat potensi kayu jenis perdagangan yaitu pada hutan primer 46.027.829 $\mathrm{m}^{3}$, hutan sekunder $113.571 .955 \mathrm{~m}^{3}$, non hutan sebesar $54.666 .920 \mathrm{~m}^{3}$ dan hutan tanaman $3.339 \mathrm{~m}^{3}$ sehingga total perkiraan potensi kayu perdagangan di Maluku adalah sebesar 214.270.044 $\mathrm{m}^{3}$ (Neraca Sumber Daya Hutan, Balai Pemantapan Kawasan Hutan Wilayah IX, Ambon, 2013). Selain potensi produksi kayu bulat yang cukup besar, Provinsi Maluku juga memiliki potensi hasil hutan bukan kayu seperti rotan, bambu, sagu, minyak kulit lawang, minyak kayu putih, damar, kopal, gaharu, anggrek, dan lain sebagainya belum di kelola secara optimal.

Pemanfaatan hutan alam di Provinsi Maluku dilakukan menjelang tahun 1960-an. Eksploitasi kayu bulat meningkat setelah menjelang tahun 1970-an setelah hadirnya perusahaan swasta nasional dibidang kehutanan seperti pemegang Izin Usaha Pemanfaatan Hasil Hutan Kayu Hutan Alam (IUPHHK-HA), Izin Usaha Pemanfaatan Hasil Hutan Kayu - Hutan Tanaman (IUPHHK-HT) dan lainnya, sehingga perkembangan pembangunan di bidang kehutanan dalam rangka mewujudkan ekonomi daerah yang semakin kokoh dan menampakan hasilnya, dimana pembangunan industri hasil hutan telah berkembang dengan cukup pesat. Jumlah IUPHHK-HA di Provinsi Maluku sebanyak 12 Unit IUPHHK-HA, tersebar pada 6 kabupaten yaitu Kabupaten Buru (4 IUPHHKHA), Kabupaten Buru Selatan (2 IUPHHK-HA), Kabupaten Maluku Tengah (3 IUPHHK-HA), Kabupaten Seram Bagian Timur (1 IUPHHKHA), Kabupaten Kep. Aru (1 IUPHHK-HA) dan Kabupaten MTB (1 IUPHHK-HA). Selain
IUPHHK-HA, terdapat juga 2 unit IUPHHK-HT yang berada di Kabupaten Buru.

Peraturan Menteri Kehutanan No. P.41/Menhut-II/2014 tentang Penatausahaan Hasil Hutan Kayu (PUHH) yang berasal dari Hutan Alam telah diubah melalui kebijakan penatasahaan hasil hutan yang dikenal dengan "kebijakan self assessment". PUHH ini merupakan aktivitas pencatatan dan pelaporan perencanaan produksi, pengukuran dan pengujian, pemanenan atau penebangan, penandaan, peredaran atau pengangkutan, serta pengolahan hasil hutan kayu. Mekanisme pelaksanaannya yaitu secara self assessment melalui SI-PUHH. Pada pelaksanaan ini peran WAS-GANISPHPL pada Dinas Kabupaten/Kota di seluruh Indonesia dalam kegiatan PUHH itu dihilangkan. Selanjutnya digantikan dengan otomatisasi melalui system secara online. Ruang lingkup PUHH kayu yang berasal dari

hutan alam meliputi seluruh hasil hutan kayu yang berasal dari hutan alam yang dimanfaatkan oleh pemegang izin sah atau pengelola hutan dan dilaksanakan secara self assessment melalui SI-PUHH Online (Dinamika Kehutanan, 2015).

Berkaitan dengan perubahan mekanisme Penatausahaan Hasil Hutan (PUHH) menggunakan SI-PUHH Online memiliki pengaruh terhadap penerimaan negara bukan pajak dan dalam tujuan untuk meningkatkan kontribusi sektor kehutanan terhadap penerimaan negara dan daerah, maka efektifitas penerapan SI-PUHH Online dalam kaitan dengan Penerimaan Negara Bukan Pajak (PNBP) pada perusahaan pemegang IUPHHK pada Hutan Produksi PT. Gema Hutani Lestari 
perlu diteliti dengan harapan kerugian Negara dan Daerah dapat terhindari/kecil..

\section{METODE PENELITIAN}

\section{Lokasi dan Waktu Penelitian}

Penelitian ini dilaksanakan di Lokasi Log Pond pemegang konsesi Izin Usaha Pemanfaatan Hasil Hutan Kayu (IUPHHK) Hutan Alam pada Hutan Produksi PT. Gema Hutani Lestari di Desa Waelanga, Kecamatan Air Buaya, Kabupaten Buru Provinsi Maluku, dan berlangsung dari bulan Juni sampai Juli 2018.

\section{Alat dan Bahan}

Alat yang akan digunakan dalam penelitian ini yaitu terdiri dari: Tally sheet, pita ukur, kalkulator, buku catatan, alat tulis-menulis, dan laptop. Sedangkan bahan yang digunakan meliputi : a) Kayu Logs hasil pengukuran GANIS PHPL yang ada di Log Pond atau Tempat Penimbunan Kayu (TPK); b) Laporan Hasil Produksi Periode Berjalan; c). Print out Data penginputan hasil pengukuran GANIS-PHPL ke dalam aplikasi SIPUHH-Online.

\section{Metode Penelitian}

Penelitian ini menggunakan metode kuantitatif dengan mengembangkan model-model matematis (perhitungan), yang berkaitan dengan pengukuran kayu bulat. Metode penelitian kuantitatif menurut Sugiyono (2015), yaitu metode penelitian yang berlandaskan terhadap filsafat positivisme dalam meneliti sample dan populasi penelitian. Tehnik pengambilan sampel dilakukan dengan acak, sedangkan pengumpulan data dilakukan dengan cara memanfaatkan instrumen penelitian yang dipakai. Langkah- langkah Pengukuran yang dilakukan di lapangan adalah sebagai berikut :

a. Semua kayu bulat rimba harus dilakukan pengukuran batang per batang untuk mengetahui isi (volume) setiap batang kayu bulat yang bersangkutan.

b. Pengukuran kayu bulat rimba dilakukan dengan cara mengukur panjang dan diameter kayu bulat. Berdasarkan panjang dan diameter kayu bulat tersebut ditetapkan isi (volume) kayu bulat dengan memperhatikan/ mengukur/ menghitung ada tidaknya cacat bontos dan cacat gubal yang mereduksi isi.

\section{Pengukuran Panjang}

a. Panjang kayu bulat rimba merupakan jarak terpendek antara kedua bontos sejajar dengan sumbu kayu bulat tersebut.

b. Panjang kayu bulat rimba diukur dalam satuan meter dengan kelipatan $10 \mathrm{~cm}$, dan pembulatan ke bawah (Peraturan Direktur Jenderal Bina Produksi Kehutanan Nomor : P.14/BIKPHH/2009, Kementerian Kehutanan, 2009).

\section{Pengukuran Diameter}

a. Pengukuran kayu bulat rimba yang berasal dari hutan alam dan hutan tanaman dengan panjang $>5 \mathrm{~m}$ :

1). Pengukuran diameter pada kedua bontos dilakukan tanpa kulit dalam satuan centimeter dengan kelipatan $1 \mathrm{~cm}$.

2). Pengukuran diameter pada tiap bontos dilakukan dengan cara mengukur garis tengah terpendek melalui pusat bontos, kemudian diukur garis tengah terpanjang juga melalui pusat bontos, dan rata-rata ukuran garis tengah dari bontos tersebut merupakan diameter dari bontos yang bersangkutan (du atau dp). 
3). Diameter kayu bulat (d) diperoleh dengan cara merataratakan ukuran diameter ujung (du) ditambah diameter pangkal (dp).

b. Pengukuran diameter kayu bulat rimba untuk kayu bulat yang berasal dari hutan tanaman dengan panjang sampai dengan $5 \mathrm{~m}$ ):

1). Pengukuran diameter pada bontos terkecil $\mathrm{Bu})$ tanpa kulit dalam satuan centimeter dengan kelipatan $1 \mathrm{~cm}$, dan pembulatan ke bawah.

2). Pengukuran diameter dilakukan dengan cara mengukur garis tengah terpendek melalui pusat bontos (B) dan garis tengah terpanjang melalui pusat bontos (B).

3). Diameter kayu bulat (d) diperoleh dengan cara merataratakan ukuran garis tengah terpendek (d1) ditambah garis tengah terpanjang $(\mathrm{d} 2)$ pada bontos ujung $(\mathrm{Bu})$.

Dalam hal kayu bulat rimba terdapat tonjolan yang panjangnya kurang dari $1 / 2$ panjang kayu bulat maka pengukuran diameter dilakukan dengan mengabaikan tonjolan tersebut, seperti pada Gambar 1.

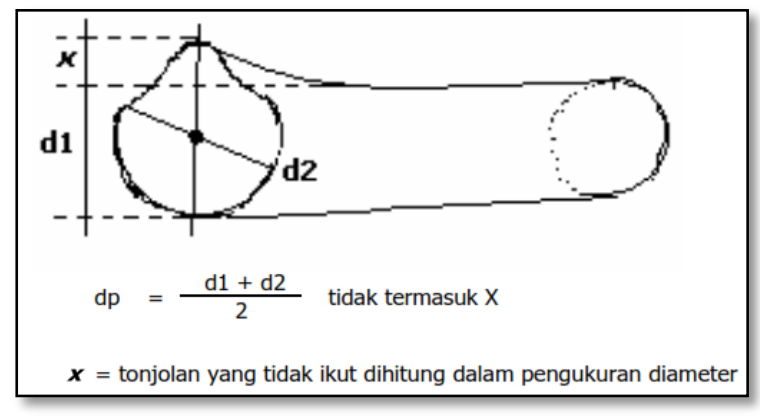

Gambar 1. Cara pengukuran kayu bulat rimba terdapat tonjolan yang panjangnya kurang dari $1 / 2$ panjang kayu bulat maka pengukuran diameter.

Dalam hal kayu bulat rimba terdapat tonjolan yang panjangnya $1 / 2$ panjang kayu bulat atau lebih maka pengukuran diameter dilakukan termasuk tonjolan, dapat dilihat pada Gambar 2
(Peraturan Direktur Jenderal Bina Produksi Kehutanan Nomor : P.14/BIKPHH/2009, Kementerian Kehutanan, 2009).

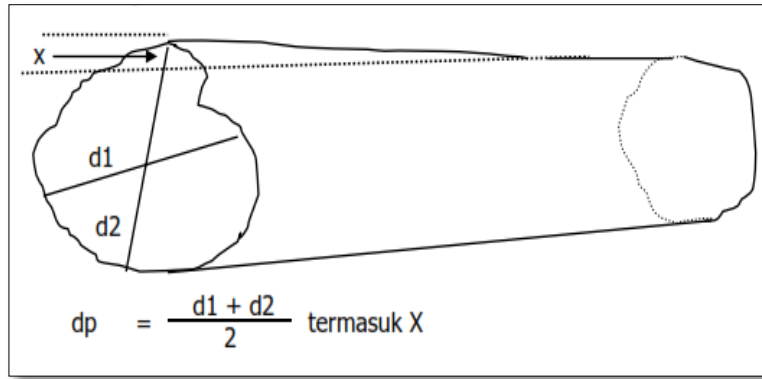

Gambar 2. Cara pengukuran kayu bulat rimba terdapat tonjolan yang panjangnya $1 / 2$ panjang kayu bulat atau lebih maka pengukuran diameter dilakukan termasuk tonjolan,

\section{Teknik Pengumpulan Data}

Data penelitian terdiri atas data primer dan data sekunder. Data primer diperoleh dari hasil pengamatan langsung di lapangan, meliputi pengumpulan data secara kuantitatif dengan cara melakukan pengukuran sampel sebanyak $10 \%$ terhadap hasil pengukuran yang dilakukan oleh GANIS-PHPL yang tertuang dalam LHP-KB. Data kuntitatif adalah Data yang berbentuk angka atau bilangan dan dapat diolah atau dianalisis menggunakan teknik perhitungan matematika.

Data sekunder adalah data pendukung dan penunjang untuk melengkapi data primer. Data ini diperoleh melalui studi pustaka berbentuk penelitian, publikasi ilmiah, peraturan perundang - undangan, dan peta yang terkait dengan penelitian yang diperoleh dari instansi terkait antara lain : Pihak Perusahaan PT. Gema Hutani Lestari, Dinas Kehutanan Provinsi Maluku dan Kementerian Lingkungan Hidup dan Kehutanan.

Laporan Hasil Penebangan Kayu Bulat (LHP-KB) didefinisikan sebagai dokumen 
tentang realisasi seluruh hasil penebangan pohon berupa kayu bulat pada petak/blok yang telah ditetapkan. Pengamatan hasil penebangan tersebut terkait kebenaran volume kayu yang telah disahkan LHPnya pada periode saat penelitian. Pengukuran kayu bulat dilakukan sebanyak 59,38 \% dari sampel yang tertuang dalam LHP-KB dengan menggunakan sistem metric yaitu mengukur panjang dan diameter (pangkal dan ujung) kayu bulat, kemudian membuat perhitungan atas dasar rumus Brereton Metric serta Tabel isi Kayu Bulat Rimba Indonesia.

\section{Analisis Data}

Data diolah secara tabulasi dan dianalisis secara kuantitatif, dengan menggunakan rumus Brereton Metric yaitu :

$$
I=\frac{0.7854 x d^{2} x p}{10.000}
$$

Dimana:

$$
\begin{array}{ll}
\text { I } & =\text { Isi kayu bulat dalam } \mathrm{m}^{3} \\
0,7854 & =1 / 4 \pi=1 / 4 \times 3.1416 \\
\mathrm{~d} & =\text { Diameter kayu dalam } \mathrm{cm} \\
\mathrm{p} & =\text { Panjang kayu dalam } \mathrm{m}
\end{array}
$$

Hasil pengukuran akan dihitung selisih jumlah volume yang tertuang dalam LHP-KB periode Juni 2018 yang merupakan hasil pengukuran GANIS-PHPL untuk mengetahui selisih persentase, kemudian dijumlahkan selisih selama bulan produksi dalam tahun RKT 2018 (bulan saat penelitian) dengan menggunakan asumsi-asumsi yang dapat dipertanggunjawabkan secara ilmiah.

Total perbedaan volume antara hasil pengukuran dilapangan dengan LHP-KB dan hasil penginputan pada SI-PUHH Online dapat digunakan sebagai dasar perhitungan besarnya kerugian Negara yang diakibatkan oleh ketidak cermatan/kelalaian pihak perusahaan bersangkutan (GANIS-PHPL) dalam proses SIPUHH Online.

\section{HASIL DAN PEMBAHASAN}

Pengujian terhadap hasil pengukuran dan pengesahan laporan hasil penebangan kayu bulat yang dilakukan oleh GANIS-PHPL pada PT. Gema Hutani Lestari dan telah disahkan LHP-KB nya, dilakukan dengan cara mengambil sampel data sebanyak 59,38 \% dari Laporan Hasil Penebangan Produksi Kayu Bulat (LHP-KB) periode Juni 2018 atau sebanyak 133 batang terhadap 3 (tiga) LHP-KB masing-masing nomor : 03/LHP-TJDB/KBS/GHL-BU/VI/2018, nomor. 03/LHP-RKT/KBS/GHL-BU/VI/2018 dan nomor. 03/LHP-RKT/KB/GHL-BU/VI/2018, tanggal 8 Juni 2018, dengan jumlah batang sebanyak 224 batang serta volume sebesar 752.22 $\mathrm{m}^{3}$.

Berdasarkan hasil pengujian terhadap panjang, diameter dan volume kayu oleh GANISPHPL sebagaimana tersebut di atas menunjukkan bahwa volume kayu sebanyak 133 batang adalah sebesar $470.16 \mathrm{M}^{3}$ atau rata-rata $3,54 \mathrm{M}^{3} /$ batang. Sementara hasil pengukuran ulang yang dilakukan oleh peneliti terhadap sample kayu yang sama sebanyak 133 batang yang telah diukur dan di LHP kan oleh GANIS-PHPL, diperoleh volume kayu bulat sebesar $500.03 \mathrm{M}^{3}$ dengan rata-rata volume per batang sebesar 3,76 $\mathbf{M}^{3}$. Hasil pengukuran selengkapnya dapat dilik]hat pada tabel 2 . 
Tabel 2. Hasil Pengujian Panjang, Dianmeter dan Volume Kayu (133 contoh uji)

\begin{tabular}{lllccc}
\hline No. & Tim Penguji & Jenis & Jumlah Batang & Volume $\left(\mathbf{m}^{\mathbf{3}}\right)$ & Rerata* $^{*}$ Volume $\left(\mathbf{m}^{\mathbf{3}} / \mathbf{b t g}\right)$ \\
\hline 1 & Ganis PHPL & Meranti & 48 & 137,76 & 2,87 \\
& & Campuran & 85 & 332,43 & 3,91 \\
& & Jumlah^ $^{\wedge}$ & & $470,16^{\wedge}$ & $3,54^{*}$ \\
2 & \multirow{2}{*}{ Peneliti } & Meranti & 48 & 143,97 & 3,00 \\
& & Campuran & 85 & 332,42 & 4,19 \\
& & Jumlah & & $500,03^{\wedge}$ & $3,76^{*}$ \\
\hline
\end{tabular}

Terdapat perbedaan volume antara hasil pengukuran GANIS PHPL dan hasil engukuran peneliti sebesar 29,87 $\mathrm{M}^{3}$, dengan selisih rata-rata volume sebesar $0,22 \mathrm{M}^{3}$ per batang. Perhitungan terhadap perbedaan tersebut dirinci sebagai berikut :

- Perbedaan selisih volume diperoleh dari volume kayu hasil pengukuran ulang oleh peneliti sebesar 500,03 $\mathrm{M}^{3}$ dikurangi volume kayu bulat hasil pengukuran GANIS PHPL sebesar 470,16 $\mathrm{M}^{3},\left(500,03 \mathrm{M}^{3}-470,16 \mathrm{M}^{3}=\right.$ 29,87 $\mathrm{M}^{3}$ ).

- Selisih rata-rata volume kayu bulat diperoleh dari jumlah total selisih volume kayu bulat dibagi dengan jumlah batang. ( 29,87 $\mathrm{M}^{3} / 133$ batang $=0,22 \mathrm{M}^{3}$ ).

Presentase toleransi terhadap hasil pengukuran kayu bulat sebesar 5,97 \% diperoleh dari jumlah selisih volume kayu bulat pengukuran peneliti dibagi jumlah volume total hasil pengukuran peneliti dikali dengan $100 \%$, $\left(29,87 \mathrm{M}^{3} / 500,03 \mathrm{M}^{3}\right.$ x $\left.100 \%=5,97 \%\right)$.

Toleransi Volume Hasil Pengukuran Kayu Bulat adalah batas penyimpangan yang masih diperkenankan. Berdasarkan pasal 74 huruf a Peraturan Pemerintah Nomor 6 Tahun 2007, toleransi volume yang diberikan sebesar 5\%, dan bila terdapat kelebihan volume yang melebihi toleransi tersebut diatas maka terdapat unsur yang merugikan Negara. Dengan demikian dari hasil perhitungan terhadap presentasi toleransi volume hasil pengukuran kayu bulat sebagaimana diatas, maka terdapat unsur yang merugikan negara, karena telah melebihi batas toleransi yang ditentukan.

Hasil penelitian menunjukkan bahwa telah terjadi selisih antara hasil pengukuran yang dilakukan oleh GANIS-PHPL dengan hasil pengukuran yang dilakukan oleh peneliti. Hal ini disebabkan karena GANIS-PHPL tidak melaksanakan tugas pengukuran terhadap panjang dan volume partai kayu bulat yang ditebang dengan baik dan benar. Akibatnya berpengaruh pada perhitungan penerimaan negara yang diproses pada aplikasi SI-PUHH Online, karena jumlah volume kayu yang terinput dalam aplikasi SI-PUHH Online menjadi dasar perhitungan besarnya penerimaan negara. Kejadian ini menunjukan bahwa pembinaan dan pengawasan secara langsung dilapangan masih dibutuhkan dalam kegiatan pengelolaan hutan sehingga penerapan self assessment dalam kegiatan pengelolaan hutan harus dikaji kembali.

Pemerintah sebenarnya bertanggung jawab mengelola sumber daya alam Indonesia untuk sebesar-besarnya kemakmuran rakyat . Berkenaan dengan hal tersebut kawasan hutan yang dikelola negara ditebang untuk 
memproduksi kayu komersial. Dari hasil tersebut Pemerintah memungut berbagai jenis royalti, retribusi dan iuran berdasarkan laporan produksi kayu. Jika kayu tersebut tidak tercatat dan/atau biaya royaltinya tidak dibayar berarti nilai ekonomi hutannya hilang dirampas. Dengan demikian tidak dapat digunakan Pemerintah untuk kesejahteraan rakyat Indonesia secara luas. Sebenarnya Presiden R.I. telah sepakat dengan Komisi Pemberantasan Korupsi (KPK) tentang pentingnya menghentikan kerugian negara di sektor kehutanan, mengkoordinasikan upayaupaya untuk memperbaiki sistem, memeriksa sistem yang memungkinkan kerugian tersebut, dan meningkatkan pemungutan penerimaan. Direktorat Penelitian dan Pengembangan Kedeputian Bidang Pencegahan Komisi Pemberantasan Korupsi R.I. telah mengkaji soal kerugian negara tersebut. Kajian tersebut memperkirakan aset negara yang hilang akibat produksi kayu yang tidak tercatat dan pemungutan penerimaan negara bukan pajak (PNBP) kehutanan yang kurang efektif selama periode 2003-2014 . Disamping itu temuan tersebut digunakan untuk menganalisa kelemahan pada sistem penata usahaan Pemerintah seputar pengawasan produksi kayu dan pemungutan PNBP (Direktorat Penelitian dan Pengembangan Kedeputian Bidang Pencegahan Komisi Pemberantasan Korupsi R.I., 2015).

Hal tersebut meskipun telah melibatkan KPK namun faktanya sampai dengan penelitian ini berakhir masih terjadi kerugian negara dari PUHH dengan sistem self assessment tersebut. Kasus ini juga banyak terjadi tidak hanya di
Maluku saja tetapi di wilayah Indonesia lainnya. Contohnya hasil temuan dari Kalimantan Barat yang juga memastikan bahwa masih terdapat kelemahan dalam pelaksanaan sistem SI-PUHH online oleh perusahaan kayu. Menurut Nugraha (2018), SI-PUHH dinilai sudah mulai advanced. SI-PUHH ini memang memberikan kemudahan bagi pelaku usaha. Karena dulu ada beberapa proses mulai dari pembuatan laporan produksi, sampai ke SK usaha, pembayaran PNBP, itu jadi satu sistem yang baik. Pada mulanya sistem tersebut untuk memotong rantai birokrasi supaya tidak terjadi korupsi. Dengan perkataan lain tidak ada demand dari birokrasi untuk tindak pidana korupsi. Melalui sistem yang dipermudah dalam level tertentu, SI-PUHH jadi persoalan akibat adanya pengawasan lemah. Dalam hal ini sangat sulit menguji ketaatan perusahaan di dalam SIPUHH. Pihak mana yang akan mengujinya ini belum ada kejelasannya dan SI-PUHH dinilai kurang transparan karena tidak memberikan akses data kepada pemantau independen. Pada SIPUHH tidak bisa dilakukan lacak balak karena pemantau independen tidak memiliki akun untuk mengecek asal kayu-kayu tebangan dari perusahaan kayu.

\section{Efektifitas Penerapan SI-PUHH Online Terhadap Penerimaan Negara Bukan Pajak \\ Untuk melindungi hutan dari perambahan,} penjarahan serta perusakan lainnya, pemerintah Indonesi menempuh berbagai cara, tujuannya tentu saja agar hutan kita tetap lestari dan hasilnya dapat dimanfaatkan sebaik mungkin.Beberapa peraturan yang ditujukan untuk melindungi hutan agar tetap lestari serat 
menjamin penerimaan negara serta legalitas hasil hutan telah dikeluarkan, antara lain adalah Permenhut No. P.55/Menhut-II/2006 jo. P.63/Menhut-II/2006 Tentang Penatausahaan Hasil Hutan yang berasal dari hutan negara dan Permenhut No. P.18/Menhut-II/2007 tentang Petunjuk Teknis dan tata cara pemungutan dan pembayaran PSDH DR.

Untuk mendukung pelaksanaannya Kementerian Lingkungan Hidup dan Kehutanan melalui Direktorat Bina Iuran dan Peredaran Hasil Hutan Direktorat Jenderal Pengelolaan Hutan Produksi Lestari membangun sistem Informasi Penatausahaan Hasil Hutan dan Penatausahaan PSDH DR berbasis teknologi informasi atau SI-PUHH Online berbasis website yang dapat di akses pada alamat http://puhh.dephut.go.id. SI-PUHH (Sistem Informasi Penatausahaan Hasil Hutan) merupakan sebuah sistem informasi untuk menyimpan transaksi data PUHH secara online, dan juga menjadi media informasi penyelenggaraan PUHH secara real-time. Perusahaan IUPHHK yang telah menjalankan Tabel.3 Kategori Tafsiran Klasifikasi N-gain

\begin{tabular}{|c|c|}
\hline Presentase (\%) & Tafsiran \\
\hline$<40$ & Tidak efektif \\
\hline $40-55$ & Kurang efektif \\
\hline $56-75$ & Cukup efektif \\
\hline$>76$ & efektif \\
\hline
\end{tabular}

SIPUHH memiliki beberapa keuntungan bila dibandingkan dengan perusahan yang belum menjalankan SI-PUHH. Keuntungan-keuntungan yang diperoleh oleh perusahaan yang telah menerapkan SIPUHH antara lain :
- Penerbitan/pembuatan SKSKB bersifat self-assessment

- Peredaran kayu bulat milik IUPHHK dapat dipantau secara real-time, oleh pihak-pihak yang terkait seperti Kementrian Kehutanan, pemilik/manajemen perusahaan, dan masyarakat.

- Pengelolaan data terpusat dan Manajemen dapat mengambil keputusan strategis dengan cepat karena dapat mengamati pergerakan log.

Implementasi SI-PUHH Online ini diharapkan dapat dirasakan manfaatnya baik bagi pemerintah maupun unit usaha, bagi dunia usaha dapat meningkatkan efektivitas dan efisiensi proses pembuatan Laporan Produksi (LHP), Pembayaran PSDH DR dan penerbitan dokumen pengangkutan atau peredaran Hasil Hutan, memberikan kepastian hukum terhadap hasil hutan yang diproduksi karena dapat dibuktikan legalitasnya melalui sistim lacak balak.Bagi pemerintah manfaat yang diperoleh dalam Implementasi SI-PUHH Online ini adalah keterlacakan kayu dari blok tebangan, Tempat Penimbunan Kayu (TPn), Tempat Pengumpulan Kayu (TPK), TPK antara hingga ke industri berikut dokumen yang menyertainya, meningkatkan monitoring penatausahaan hasil hutan, dan memudahkan perekaman data dan pelaporan penatausahaan hasil hutan.

Secara umum dengan menerapkan SIPUHH Online verifikasi dokumen dan tanda sah atau legalitas hasil hutan dapat dilaksanakan dengan cepat dan akurat tanpa kendala ruang dan 
waktu, demikian pula dengan penelusuran setiap batang logs atau lacak balak. Dari sisi kontribusi terhadap penerimaan negara bukan pajak (PNBP) penerapan SI-PUHH online menurut Direktorat Jenderal Pengelolaan Hutan Produksi Lestari cukup baik dan efektif karena telah terintegrasi dengan Sistim Informasi Penerimaan Negara Bukan Pajak (SI-PNBP) sehingga semua penerimaan negara dapat dipantau secara real time.(https ://www. Mongabay. co.id/2017/09/04/ ketika kementerian lingkungan dan kehutanan integrasikan sistem informasi kelola hutan / diakses pada tanggal 12 Pebruari 2019).

Untuk menguji Efektifitas dari Penerapan SI-PUHH Online dalam kaitan dengan Penerimaan Negara Bukan Pajak melalui proses input data volume kayu bulat dalam aplikasi SIPUHH online oleh Tenaga Teknis Perusahaan dilakukan Uji Normalitas Gain ( $\mathrm{N}$-Gain) terhadap hasil penelitian pengukuran volume kayu bulat yang dilakukan. Kategori Tafsiran efektivitas N-Gain (menurut Hake, R.R. 1999) pada tabel 3 berikut.

Berdasarkan tabel hasil perhitungan uji $\mathrm{N}$-gain, menunjukan bahwa nilai rata-rata $\mathrm{N}$-gain score untuk hasil pengukuran volume kayu bulat yang dilakukan olehpeneliti adalah sebesar 99.7512 ataau $99.75 \%$, termasuk dalam kategori Efektif, dengan nilai $\mathrm{N}$-gain score minimal $99.35 \%$ dan maksimal $99.97 \%$. Dengan demikian dapat disimpulkan bahwa penerapan SI-PUHH Online dalam kaitan dengan Penerimaan Negara Bukan Pajak (PNBP) Efektif untuk meningkatkan penerimaan negara bukan pajak, karena memilki tingkat presentasi diatas 76 persen. IUPHHK PT.
Gema Hutan Lestari merupakan salah salah pemegang konsesi di Provinsi Maluku yang telah mendapatkan sertifikat Pengelolaan Hutan Produksi Lestari skema Madatory dengan kategori kinerja baik yang berlaku mulai tanggal 15 Januari 2015 s/d 14 Januari 2020, itu artinya seluruh tahapan dalam penerapan SI-PUHH Online telah dilengkapi dan dipenuhi oleh PT. Gema Hutani Lestari serta telah dilaksanakan dengan efektif.

Hal itu ditunjukan dari hasil pengumpulan data sekunder meliputi dokumen sumber berupa Laporan Hasil Produksi (LHP) yang digunakan GANIS-PHPL PT. Gema Hutani Lestari telah berbasis SI PUHH Online. Namun pada sisi lain data primer yang diperoleh peneliti saat melakukan pengukuran ulang terhadap sampel kayu yang sama, ternyata masih terjadi selisih volume kayu bulat yang melebihi batas toleransi yang ditetapkan walaupun tidak signifikan, sehingga berdampak pada terjadinya unsur kerugian negara.

\section{KESIMPULAN}

1. Perbedaan selisih volume kayu bulat sebesar 29,87 $\mathbf{M}^{3}$, dengan selisih rata-rata volume kayu bulat sebesar $\mathbf{0 , 2 2} \boldsymbol{M}^{3}$. Kelebihan prosentasi toleransi terhadap hasil pengukuran kayu bulat sebesar 5,97 \% dari batas toleransi $5 \%$ yang diberikan.

2. Analisis Perbedaan Rata-Rata antara Hasil Pengukuran GANIS-PHPL dan Peneliti dengan menggunakan Uji Independen Sample T Test (Uji T), menunjukan bahwa tidak terdapat perbedaan yang signifikan 
antara volume hasil pengukuran tenaga teknis perusahaan dan peneliti. Hasil uji parametrik (equal variance assumsed) diperoleh nilai signifikan (Sig 2.tailed), sebesar 0.368 nilai signifikan $(\mathrm{Sig})>$ dari 0,05 . Sementara untuk perbedaan rata-rata (mean difference) antara volume hasil pengukuran tenaga teknis dan peneliti adalah sebesar 0,22406. Nilai perbedaan rata-rata inilah yang dijadikan dasar untuk penghitungan kerugian negara.

3. Selisih hasil pengukuran yang dilakukan GANIS-PHPL dalam melakukan pemeriksaan dan pengukuruan partai kayu sesuai dengan kewenangannya, maka ditaksir telah terjadi kerugian Negara dari hasil produksi kayu bulat untuk periode bulan Juni 2018 sebesar Rp. 11.405.120,00 dengan rincian untuk PSDH sebesar Rp. 2.644.080,00; dan DR sebesar Rp. 8.741.080,00.

4. Seluruh kegiatan Penatausahaan Hasil Hutan yang dilakukan oleh PT. Gema Hutan Lestari seluruhnya telah berbasis SI-PUHH Online karena data dapat diakses secara real time dan Up to Date.

5. Penerapan SI-PUHH Online dalam kaitan dengan penerimaan negara bukan pajak (PNBP) masuk kategori Efektif karena nilai rata-rata N-Gain score sebesar $99.78 \%$ atau lebih lebih dari $76 \%$, dengan nilai N-gain score minimal $99.35 \%$ dan maksimal 99,97 $\%$.

\section{DAFTAR PUSTAKA}

Dinamika Kehutanan. 2015. Apa Saja Sih Perubahan Sebelum dan Sesudah Kebijakan Penatausahaan Hasil Hutan secara Self Assessment.

http://https://aguraforestry.wordpress.c om/tag/penatausahaan-hasil-hutan/.

Diakses 1 Agustus 2019)

Direktorat Penelitian dan Pengembangan Kedeputian Bidang Pencegahan Komisi Pemberantasan Korupsi R.I. 2015. Mencegah Kerugian Negara Di Sektor KehutananSebuah Kajian Tentang Sistem Penerimaan Negara Bukan Pajak Dan Penatausahaan Kayu. http://https://media.neliti.com/media/pu blications/45225-ID-mencegahkerugian-negara-di-sektor-kehutanansebuah-kajian-tentang-sistempeneri.pdf. Diakses 15 Agustus 2019.

Dinas Kehutanan Provinsi Maluku. 2016. Statistik Kehutananan 2016, Dinas Kehutanan Provinsi Maluku, Ambon.

Manuhuwa, E. 2009. Hasil Hutan Bukan Kayu Sebagai Bagian Dari Pembangunan Hutan Di Maluku. Pidato Pengukuhan Jabatan Guru Besar Dalam Jurusan Kehutanan Fakultas Pertanian Universitas Pattimura.

Nugraha, I. 2018. Koalisi Ungkap Kelemahan Sistem Informasi Hasil Hutan, Apa Kata Menteri Siti? http:// www.mongabay.co.id/2018/11/14/koa lisi-ungkap-kelemahan-sisteminformasi-hasil-hutan-apa-katamenteri-siti/. Diakses 21 Agustus 2019.

Republik Indonesia. 1999. Undang-Undang Nomor 41 Tahun 1999 tentang Kehutanan, Sekretaris Negara RI, Jakarta.

Republik Indonesia. 2004. Undang-Undang Nomor 23 Tahun 2004 tentang 
Pemerintahan Daerah, Sekretaris Negara RI Jakarta.

Republik Indonesia. 2009. Peraturan Direktur Jenderal Bina Produksi Kehutanan Nomor P.14/VIBIKPHH/2009 Tentang Metoda Pengukuran dan Tabel Isi Kayu Bulat Rimba Indonesia, Biro Hukum dan Organisasi Departemen Kehutanan RI Jakarta. 